\title{
THREE DIMENSIONAL CUTTING PROBLEM: AN INTEGER PROGRAMMING APPROACH
}

\author{
Bayram Kahraman \\ Department of Mining Engineering \\ Dokuz Eylul University, Tinaztepe Kampusu, 35160 \\ Buca, İzmir, Turkey \\ bayram.kahraman@deu.edu.tr
}

\begin{abstract}
Cutting problem is one of the major problems faced in marble factories. Huge marble blocks coming from marble quarries are first cut into planes according to their depths. Then these planes are sized according to the length and width of the demanded products. In this study, cutting problem of a marble factory is handled. The two problems, which are cutting marble blocks into planes and sizing these planes, are integrated together. An integer programming model is built for the integrated problem. The objective of the model is to minimize total waste of marble while finding the cutting design of the marble block and marble planes. The model is used to solve the cutting problem of a real life marble processing factory. It is shown that the mathematical model decreases wasted amount of marble considerably compared to the industry average.
\end{abstract}

Key Words- Cutting problem, Integer Programming, Marble Processing Industry

\section{INTRODUCTION}

Cutting plane problems have very many applications in industry and are well known problems in literature [1]. One of the industries which face cutting plane problems in a considerable way is the marble processing industry. These factories supply huge marble blocks from marble quarries and turn these into fine stones to be covered on house, office or outdoor floors and surfaces. The two main operations in marble factories are cutting the marble blocks into marble planes (Figure 1) and cutting marble planes according to the length and width of the final products (Figure 2).

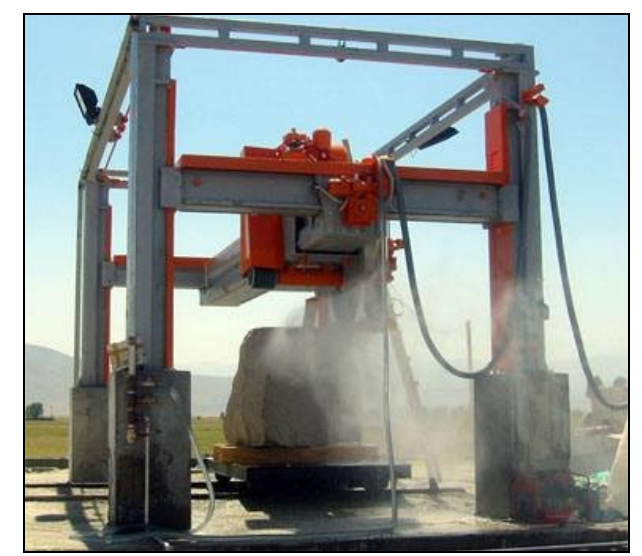

Figure 1. Cutting marble block into planes. 


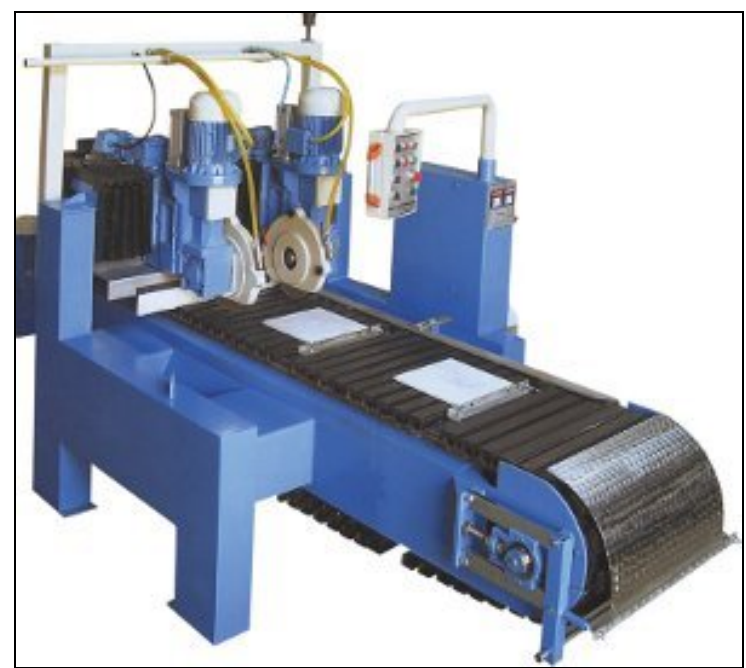

Figure 2. Cutting marble planes into finished products

Due to the nature of cutting operations, spoilage is of major concern in marble factories. Spoilage of marbles cause many problems to the managers of marble factories. Firstly, material costs of products increase as waste increases. In addition, spoiled marbles consume quite a large amount of area. Hence the factory needs to hire or buy more area to do its operations properly. Finally, more costs are incurred in order to remove wastes from the factory site (Figure 3).

In this paper, both cutting operations; cutting the marble blocks into planes and cutting planes into finished products; are handled together. Since the output of the first operation feeds the second operation, the two cutting operations should be planned together to minimize waste. The purpose of this paper is to develop a procedure to prepare cutting plans of marble blocks and planes to minimize waste of marble. In order to do so, an integer programming (IP) model is built, which integrates both operations together. The model handles the classical cutting plane problem but also considers the third dimension which is the depth. The objective of the model is to minimize total waste of marble while giving the cutting patterns of the marble blocks and planes. Also, a real life cutting problem of a marble factory is solved using the proposed approach.

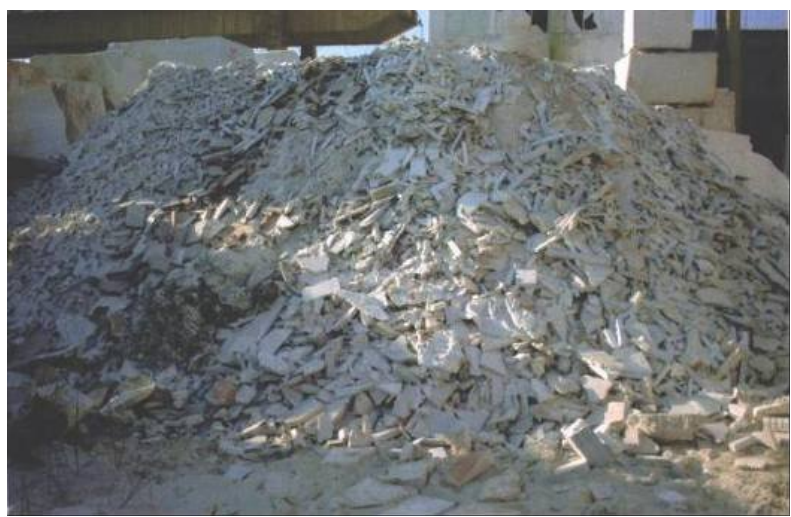

Figure 3. Waste of marble in a marble factory. 
The rest of the paper is organized as follows. In section two the problem is defined. In section three, proposed approach is explained in detail. Section four gives the real life marble cutting problem and computational results. Finally, conclusions and future research are given in section five.

\section{PROBLEM OVERVIEW}

Turkey owns 5,2 billion $\mathrm{m}^{3}$ marble reserves which make up $40 \%$ of the worlds marble reserves. Marble production in Turkey has started to grow since 1980s. Today, Turkey is the $7^{\text {th }}$ marble producer of the world. All around the country, there exists 563 marble block producers and over 1000 fine stone producers [2].

Within these factories, $1150000 \mathrm{~m}^{3}$ marble blocks are processed to produce fine stones in 2002. The level of waste in these factories turns out to be around \%20 [2]. That means $230000 \mathrm{~m}^{3}$ of marble is wasted only in 2002. Most of this amount is caused by selecting wrong cutting patterns when cutting marble blocks into planes and cutting marble planes into final dimensioned products.

In this study, in order to minimize wastes occurring from cutting operations, an IP model is built. The model handles both cutting operations and finds cutting patterns to both of them together while minimizing total waste of marble.

\section{PROPOSED APPROACH}

In marble processing factories huge marble blocks coming from quarries are first prepared as a rectangular prism with uniform dimensions. Then these blocks go through the first cutting operation where the block is cut into marble planes through the depth dimension.

During this operation some of the block is wasted. For example consider a block with $200 \mathrm{~cm} \times 200 \mathrm{~cm} \times 100 \mathrm{~cm}$ dimensions. If the depth of the block is $100 \mathrm{~cm}$ and the depth of planes to be cut is $3 \mathrm{~cm}$ then, 33 planes will be cut out of the block leaving $1 \mathrm{~cm}$ back. This last $1 \mathrm{~cm}$ plane cannot be used for any other product (too thin) so that it brings out a waste of $40000 \mathrm{~cm}^{3}(200 \mathrm{~cm} \times 200 \mathrm{~cm} \times 1 \mathrm{~cm})$ marble. This situation is also represented in Figure 4 below. The dashed lines represent the planes to be cut out of the block and the remaining volume in the block (wasted marble) is shown by the shaded region.

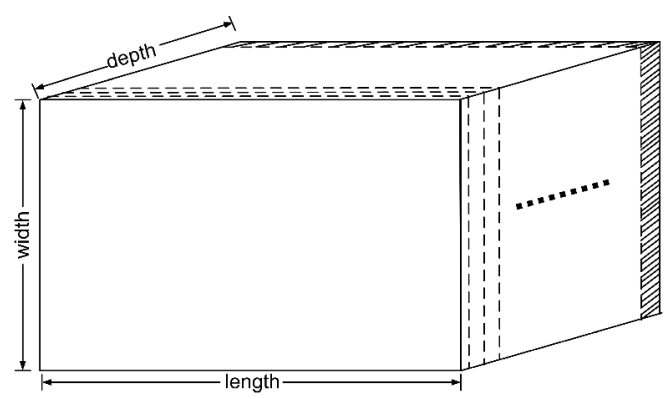

Figure 4. Sample marble block cutting pattern 
After cutting the marble block into planes comes the second cutting operation. This operation consists of cutting marble planes according to the final products dimensions. Similar to block cutting, more wastes are incurred in this operation to the cutting pattern of the plane. An example cutting pattern can be seen in Figure 5. In the figure, 15 products are cut out of the plane and the shaded region is the wasted marble.

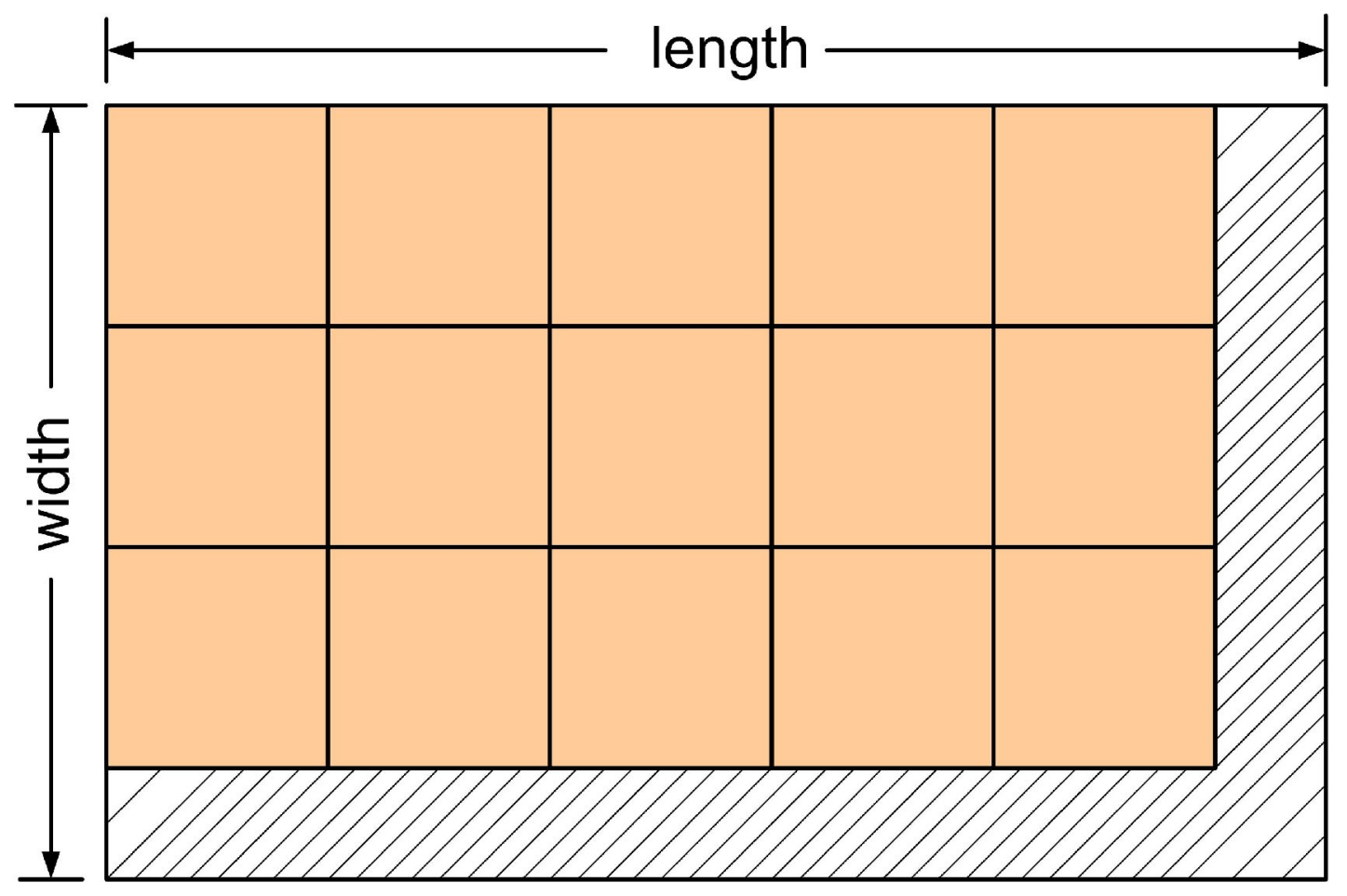

Figure 5. Sample marble plane cutting pattern

In real life, most of the time a factory has to deal with more than one type of a product. When this is the case, looking at Figures 4 and 5, it can be said that it is possible to lower wasted marble amount by applying different cutting patterns. In this study, an integer programming model is built to deal with both cutting operations. The model outputs the cutting patterns of marble blocks and planes while minimizing total wasted amount of marble. The notation used in the model is given in Table 1.

The model built is given with Equations 1 to 6 below. Equation 1 is the objective function which states that the total wasted amount of marble from the two cutting operations should be minimized. Equation 2 is the set of constraints which guarantees that the demand is satisfied. Equation 3 builds the relation between cutting blocks and cutting planes operations. It states that the number of planes cut from the block should not be exceeded in the cutting planes operation. Equation 4 states the available number of blocks to be used. Finally, equation 5 set the decision variables $\mathrm{X}$ and $\mathrm{Y}$ to be integers. 
Table 1. Notation used in the model.

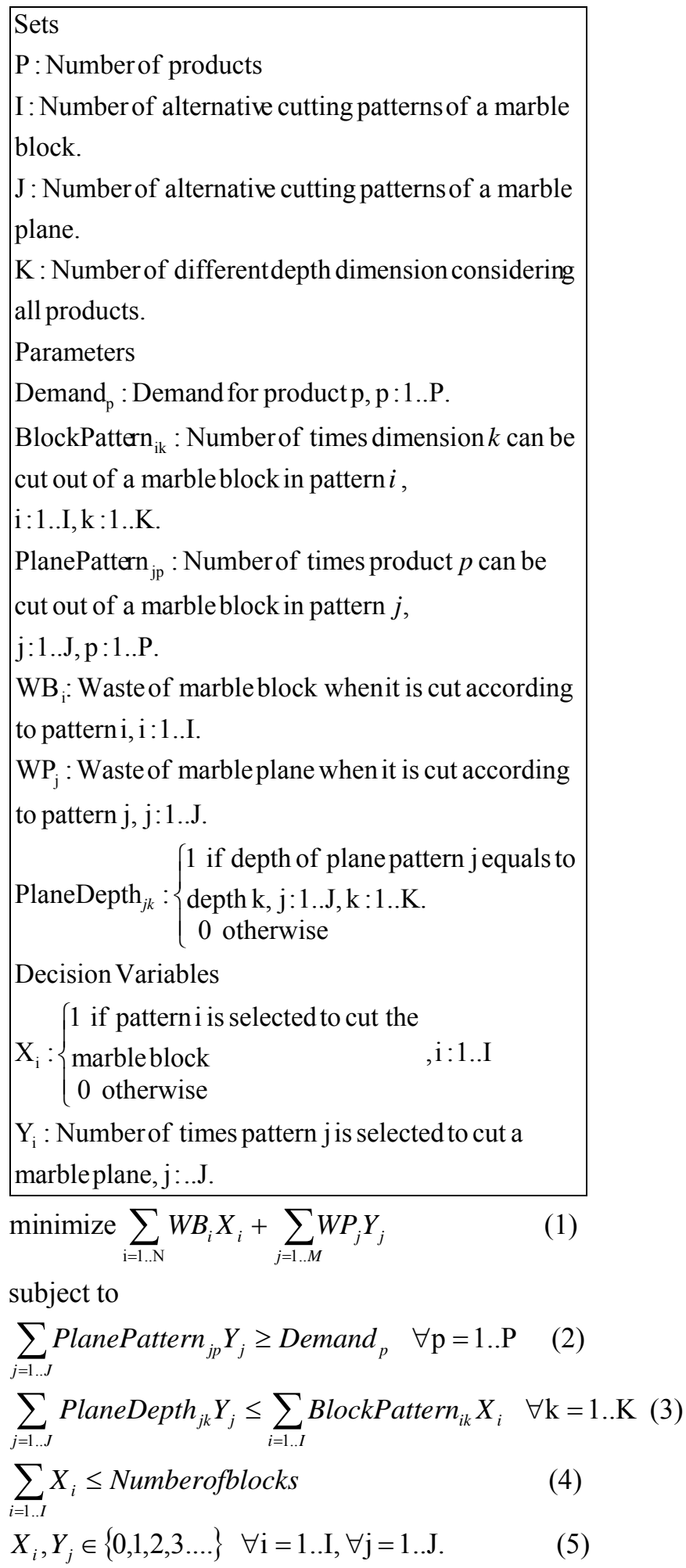

When the model is solved, optimum cutting patterns and the corresponding amount of marble waste is obtained. 


\section{REAL LIFE MARBLE CUTTING PROBLEM}

In this paper the cutting problem of a marble processing factory operating in Afyon region is handled. The factory has received an order including four different products. The products, their dimensions and demanded units are given in Table 2 below. The dimensions of the marble blocks supplied to produce this order are $220 \mathrm{~cm} \times 140 \mathrm{~cm} \times 108 \mathrm{~cm}$.

Table 2. Products required.

\begin{tabular}{|c|c|c|c|c|}
\hline & A & B & C & D \\
\hline Dimensions (cm) & $60 \times 30 \times 3$ & $40 \times 40 \times 3$ & $40 \times 40 \times 2$ & $30 \times 30 \times 2$ \\
Demand (unit) & 3200 & 900 & 6000 & 700 \\
\hline
\end{tabular}

It can be seen from Table 2 that there exists two different products thicknesses. These are $3 \mathrm{~cm}$ thick products $(\mathrm{A}$ and $\mathrm{B}) 2 \mathrm{~cm}$ thick products $(\mathrm{C}$ and $\mathrm{D})$. Considering these two thickness values and the depth of the marble blocks supplied, alternative cutting patterns are listed in Table 3. For example, pattern 1 in Table 3 means that 54 times $2 \mathrm{~cm}$-thick planes will be cut out of the block. Therefore there will be no wasted marble. Pattern 2 says, 52 times $2 \mathrm{~cm}$-thick planes and $13 \mathrm{~cm}$-thick plane will be cut out of the block. When this is the case, $30800 \mathrm{~cm}^{3}$ marble would be wasted $(220 \mathrm{~cm} \times 140 \mathrm{~cm} \times 1 \mathrm{~cm})$.

Similarly, alternative cutting patterns of a marble plane are generated and listed in Table 4. The first 11 patterns are for products $A$ and $B$, which are $3 \mathrm{~cm}$-thick products, and the rest 16 patterns are for products $C$ and $D$ which are $2 \mathrm{~cm}$-thick products. The important point is that we cannot cut two products with different thicknesses out of the same plane. An example cutting pattern is given in Figure 6 in order to show how to read Table 4. Pattern 6 in Table 4 states to cut 8 of product A and 9 of product B from the plane. This cutting pattern can be seen in Figure 6 . The shaded region in the figure shows the wasted amount of marble which is $6000 \mathrm{~cm}^{3}$.

The model is written and solved in Lingo optimization software. In the solution, the selected cutting patterns for block cutting turned out to be pattern 3 and pattern 11 . 13 blocks are cut according to pattern 3 and 11 blocks are cut according to pattern 35 . For cutting planes operation the selected patterns and number of times to be performed are given in Table 5. As seen from Table 5, patterns 6, 18 and 20 are selected. That means 400 planes are cut according to pattern $6 ; 663$ planes are cut according to pattern 18 and 3 planes are cut according to pattern 20 . When these patterns are applied, the total wasted marble amount turns out to be around $5,07 \mathrm{~m}^{3}$. This corresponds to about $6,3 \%$ waste which is far less than $20 \%$. 
Table 3. Alternative cutting patterns of a Table 4. Alternative cutting patterns of a marble block.

\begin{tabular}{|c|c|c|c|}
\hline \multirow{2}{*}{ Pattern } & \multicolumn{2}{|c|}{ Depth } & \multirow{2}{*}{$\begin{array}{l}\text { Waste } \\
\left(\mathrm{cm}^{3}\right)\end{array}$} \\
\hline & $2 \mathrm{~cm}$ & $3 \mathrm{~cm}$ & \\
\hline 1 & 54 & 0 & 0 \\
\hline 2 & 52 & 1 & 30800 \\
\hline 3 & 51 & 2 & 0 \\
\hline 4 & 49 & 3 & 30800 \\
\hline 5 & 48 & 4 & 0 \\
\hline 6 & 46 & 5 & 30800 \\
\hline 7 & 45 & 6 & 0 \\
\hline 8 & 43 & 7 & 30800 \\
\hline 9 & 42 & 8 & 0 \\
\hline 10 & 40 & 9 & 30800 \\
\hline 11 & 39 & 10 & 0 \\
\hline 12 & 37 & 11 & 30800 \\
\hline 13 & 36 & 12 & 0 \\
\hline 14 & 34 & 13 & 30800 \\
\hline 15 & 33 & 14 & 0 \\
\hline 16 & 31 & 15 & 30800 \\
\hline 17 & 30 & 16 & 0 \\
\hline 18 & 28 & 17 & 30800 \\
\hline 19 & 27 & 18 & 0 \\
\hline 20 & 25 & 19 & 30800 \\
\hline 21 & 24 & 20 & 0 \\
\hline 22 & 22 & 21 & 30800 \\
\hline 23 & 21 & 22 & 0 \\
\hline 24 & 19 & 23 & 30800 \\
\hline 25 & 18 & 24 & 0 \\
\hline 26 & 16 & 25 & 30800 \\
\hline 27 & 15 & 26 & 0 \\
\hline 28 & 13 & 27 & 30800 \\
\hline 29 & 12 & 28 & 0 \\
\hline 30 & 10 & 29 & 30800 \\
\hline 31 & 9 & 30 & 0 \\
\hline 32 & 7 & 31 & 30800 \\
\hline 33 & 6 & 32 & 0 \\
\hline 34 & 4 & 33 & 30800 \\
\hline 35 & 3 & 34 & 0 \\
\hline 36 & 1 & 35 & 30800 \\
\hline 37 & 0 & 36 & 0 \\
\hline
\end{tabular}

\begin{tabular}{|c|c|c|c|c|c|}
\hline Pattern & $\mathbf{A}$ & $\mathbf{B}$ & $\mathbf{C}$ & $\mathbf{D}$ & Waste $\left(\mathbf{c m}^{\mathbf{3}}\right)$ \\
\hline $\mathbf{1}$ & 14 & 0 & 0 & 0 & 16800 \\
$\mathbf{2}$ & 13 & 2 & 0 & 0 & 12600 \\
$\mathbf{3}$ & 12 & 3 & 0 & 0 & 13200 \\
$\mathbf{4}$ & 10 & 5 & 0 & 0 & 14400 \\
$\mathbf{5}$ & 9 & 7 & 0 & 0 & 10200 \\
$\mathbf{6}$ & 8 & 9 & 0 & 0 & 6000 \\
$\mathbf{7}$ & 6 & 11 & 0 & 0 & 7200 \\
$\mathbf{8}$ & 4 & 12 & 0 & 0 & 13200 \\
$\mathbf{9}$ & 3 & 13 & 0 & 0 & 13800 \\
$\mathbf{1 0}$ & 2 & 14 & 0 & 0 & 14400 \\
$\mathbf{1 1}$ & 0 & 15 & 0 & 0 & 20400 \\
$\mathbf{1 2}$ & 0 & 0 & 15 & 0 & 13600 \\
$\mathbf{1 3}$ & 0 & 0 & 14 & 4 & 9600 \\
$\mathbf{1 4}$ & 0 & 0 & 13 & 6 & 9200 \\
$\mathbf{1 5}$ & 0 & 0 & 12 & 8 & 8800 \\
$\mathbf{1 6}$ & 0 & 0 & 11 & 10 & 8400 \\
$\mathbf{1 7}$ & 0 & 0 & 10 & 12 & 8000 \\
$\mathbf{1 8}$ & 0 & 0 & 9 & 16 & 4000 \\
$\mathbf{1 9}$ & 0 & 0 & 8 & 18 & 3600 \\
$\mathbf{2 0}$ & 0 & 0 & 7 & 19 & 5000 \\
$\mathbf{2 1}$ & 0 & 0 & 6 & 20 & 6400 \\
$\mathbf{2 2}$ & 0 & 0 & 5 & 21 & 7800 \\
$\mathbf{2 3}$ & 0 & 0 & 4 & 22 & 9200 \\
$\mathbf{2 4}$ & 0 & 0 & 3 & 24 & 8800 \\
$\mathbf{2 5}$ & 0 & 0 & 2 & 26 & 8400 \\
$\mathbf{2 6}$ & 0 & 0 & 1 & 27 & 9800 \\
$\mathbf{2 7}$ & 0 & 0 & 0 & 28 & 11200 \\
\hline
\end{tabular}




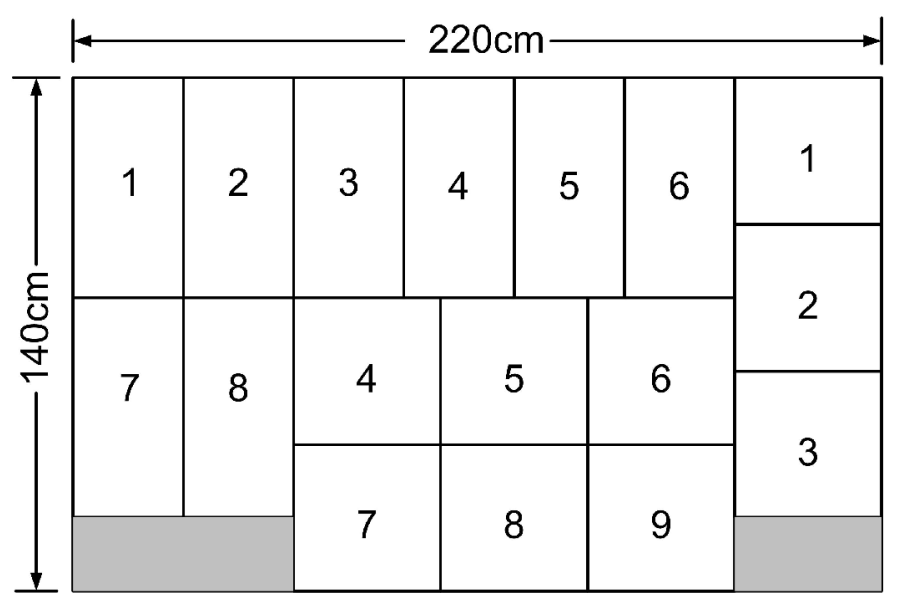

Figure 6. Cutting pattern 6 from Table 4.

Table 5. Selected cutting patterns of planes

\begin{tabular}{|c|c|}
\hline Selected Patterns & Number of planes to be cut in this pattern \\
\hline 6 & 400 \\
\hline 18 & 664 \\
\hline 20 & 3 \\
\hline
\end{tabular}

\section{CONCLUSION AND FUTURE RESEARCH}

In this study, the cutting problem which is a major problem of marble processing industry is handled. Today, Turkish marble processing industry operates with $20 \%$ waste on the average. Most of this amount is caused by selecting wrong cutting patterns in cutting operations. The two main cutting operations in a marble processing factory which are cutting marble blocks into planes and cutting marble planes into final products dimensions, are handled together. An IP model is built to minimize total wasted amount of marble and to find the optimum cutting patterns for both operations. The proposed approach is employed to solve the cutting problem of a marble processing factory in Afyon region. The results showed that average amount of waste decreases to $6,3 \%$ which is much better than the industry average, $20 \%$.

\section{REFERENCES}

1. Winston, L. W, Operations research applications and algorithms, Duxbury Press USA, 1994.

2. Ozturk, M, Pollution caused by marble cutting, Turkish National Assembly Environment Commission, 2009. 